5 Popp. R. L., Wolfe, S. B., Hirata, T., and Feigenbaum, H., American fournal of Cardiology, 1969, 24, 523.

${ }_{16}$ Wolfe, S. B., Popp, R. L., and Feigenbaum, H., Circulation, 1969, 39, 615 .

17 Feigenbaum, H., Waldhausen, J. A., and Hyde, L. P., Fournal of the American Medical Association, 1965, 191, 711.

8 Moss, A. J., and Bruhn, F., New England fournal of Medicine, 1966, 274, 380 .

19 Pridie, R. B., and Turnbull, T. A., British Medical fournal, 1968, 3, 356.

20 Chesler, E., Joffe, H. S., Vecht, R., Beck, W., and Schrite, V., Circulation, 1970, 42, 123 .

\section{The Kveim Test}

The skin test for sarcoidosis known as the Kveim test was introduced by A. Kveim in $1941^{1}$. In essence it consists of an intradermal injection of $0.15-0.20 \mathrm{ml}$ of a fine suspension in saline of material from a granulomatous lymph node taken from a patient with active disease. A positive reaction, which takes 4 to 6 weeks to develop, appears as a firm nodule 3-8 $\mathrm{mm}$ in diameter. Histological examination shows it to be composed of collections of epithelioid cells in small tubercles, usually associated with multinucleate giant cells and a few lymphocytes.

The reliability of the test depends largely on the test material itself, and batches prepared in apparently identical fashion may vary widely in their activity. It is therefore essential that any material used for diagnostic purposes should be adequately standardized against material of known activity. With a satisfactory reagent positive reactions are obtained in about $80 \%$ of patients in which the diagnosis has been histologically confirmed and in $50 \%$ in which the diagnosis has been made on purely clinical grounds. ${ }^{2}$ False positive reactions have been reported in only about $2 \%$ of persons tested. The highest incidence of positive reactions is said to occur in acute cases, being lower in subacute and chronically active cases and down to about $33 \%$ in the inactive cases.

Whereas a positive Kveim test is generally accepted as evidence of sarcoidosis, the mechanism of the test is obscure. There is at present virtually no evidence to support the view that a positive reaction is based on an immune response to a unique aetiological agent, though this was presumably the theoretical basis of the original test. There is no need to postulate a living aetiological agent, since an essentially similar reaction is given to zirconium or beryllium in individuals sensitive to these elements. ${ }^{3} 4$

Though a positive Kveim test probably results from an unusual type of immunological reaction to some constituent of the test antigen, a recent study by $\mathrm{H}$. L. Israel and $\mathrm{R}$. A. Goldstein $^{5}$ throws considerable doubt on its specificity for sarcoidosis. They found, for example, that in 37 selected cases of sarcoidosis there was no correlation with either activity or duration of the disease but only with the presence of hilar or mediastinal lymphadenopathy. Thus the test was positive in all 14 patients with chronic inactive disease in which these nodes had remained radiologically enlarged, even up to 26 years, whereas in 12 patients with subacute disease but with minimal hilar node enlargement only one positive reaction was obtained. Moreover, of 11 patients with sarcoid granulomata of the skin or liver but with normal lungs and hilar nodes only one gave a positive reaction.

To support their interpretation of these results-namely, that a positive Kveim test is more closely related to lymphadenopathy than to sarcoidosis-these authors tested 12 patients with non-sarcoid lymphadenopathies with the fol- lowing positive results: Hodgkin's disease and histoplasmosis each 0 out of 2 ; chronic lymphatic leukaemia and glandular tuberculosis each 2 out of 2 ; infectious mononucleosis 1 out of 3 ; and nonspecific cervical adenitis 1 out of 1 . That is a total of 6 positive reactors out of 12 cases.

Israel and Goldstein emphasize that a comparative test of their Kveim antigen (Commonwealth Serum Laboratory) with the standard Chase-Siltzbach material showed no significant difference. ${ }^{6}$ They also draw attention to the results of W. C. Maddrey and colleagues, ${ }^{7}$ who found that in 12 patients with sarcoid granulomata of the liver all 6 with enlargement of hilar nodes were Kveim-positive, whereas out of the 6 without lymph node enlargement were Kveim-negagive. Further support for the nonspecific nature of the Kveim test may also be adduced from the findings of D. N. Mitchell and his colleagues ${ }^{8}$ that positive Kveim tests may occur in about $50 \%$ of cases of Crohn's disease. It would therefore appear that Israel and Goldstein's conclusions that "the specificity of the Kveim antigen reaction ... is open to question" is justified.

Kveim, A., Nordisk Medicin, 1941, 9, 169.

2 Siltzbach, L. E., American Review of Respiratory Diseases, 1961, Supplement, 89 .

ment, 89

W. B., Transactions of the St. John's Hospital Dermatological Society, 1957, No. 39, p. 1 .

- Sneddon, L. B., Postgraduate Medical fournal, 1958, 34, 262.

Israel, H. L., and Goldstein, R. A., New England fournal of Medicine, $1971,284,345$.

- Hurley, T. H., and Bartholomew, C., La Sarcoidose, p. 194. Paris, Masson, 1967

7 Maddrey, W. C., Johns, C. J., Boitnott, J. K., and Iber, F. L., Medicine, $1970,49,375$

${ }^{8}$ Mitchell, D. N., Cannon, P., Dyer, N. H., Hinson, K. F. W., and Willoughby, J. M. T., Lancet, 1970, 2, 496.

\section{Ascorbic Acid and Pressure Sores}

Cutaneous sensory loss, ischaemia, direct pressure, tissue hypoxia, anaemia, infection, protein deficiency, and urinary and faecal incontinence appear to be the main factors responsible for the formation and delayed healing of pressure sores in patients suffering from paraplegia and tetraplegia. ${ }^{1-3}$ For many years it has been thought that deficiency of

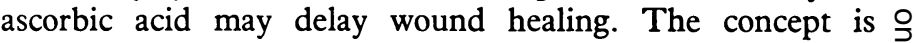
supported by the fact that this vitamin is necessary for the $N$ normal synthesis and maintenance of collagen in the repair $\rightarrow$ of tissues. When the ascorbic acid is deficient, the hydroxylation of proline and lysine to hydroxyproline is inhibited. ${ }^{4}$ In $\mathrm{N}$ such circumstances proline and lysine combine to form proto- N collagen, a polypeptide of high molecular weight, and hyaluronic acid also accumulates. ${ }^{6}$

In a study of the healing of wounds J. E. Dunphy and K. N. Udupa ${ }^{7}$ noted that in the initial productive phase of $\stackrel{\mathscr{P}}{\rightarrow}$ about five days mast cells produced mucopolysaccharides and fibroblasts produced soluble protein precursors of $\frac{\vec{\Phi}}{\Phi}$ collagen. Normal collagen fibres were then formed in the $\frac{\rho}{\mathbb{P}}$ second or collagen phase of about five days up to the completion of wound healing. These workers found that in rats deficient in protein both phases were delayed, but the situation could be restored to normal by giving methionine. In guinea-pigs rendered scorbutic the productive phase was $\stackrel{\overline{0}}{\bar{F}}$ prolonged, but little collagen was formed; 48 hours after giving ascorbic acid the wound passed into the collagen phase. 
It is not surprising, therefore, that the role of ascorbic acid should have been studied in relation to the pathogenesis and treatment of pressure sores. T. Hunter and K. T. Rajan ${ }^{8}$ now report the results of their investigations in 18 paraplegic patients aged from 16 to 71 years, of whom nine had pressure sores and nine had not. The results of vitamin $C$ saturation tests in these 18 cases were compared with those obtained on eight normal controls aged from 23 to 35 . In addition biopsies of skin and connective tissue were taken from the edge of the pressure sore in seven patients, five of whom were treated surgically immediately afterwards, and in two cases a second biopsy was made after saturation with vitamin C. Seven out of eight controls reached vitamin C saturation in 72 hours, while six out of nine of the group with sores and five out of the nine without sores took longer than 72 hours. Though the authors have not analysed their findings statistically, it seems that there was some difference between the findings in the paraplegic group and in the controls. But no apparent difference was noted in paraplegics with or without pressure sores. Histological studies in the two cases undergoing biopsy before and after saturation with ascorbic acid suggested that the administration of the vitamin considerably increased the formation of collagen. These preliminary and somewhat inconclusive results suggest that the part played by ascorbic acid in relation to the aetiology and healing of pressure sores deserves further study.

1 Bains, J. W., Crawford, D. T., and Ketcham, A. S., Annals of Surgery, 1966, 164, 243

Smith, M., and Enquist, I. F., Surgery, Gynecology and Obstetrics, 1967, 125, 965.

3 Kermani, S. R., Siddiqui, M., Zain, S., and Kazi, Z. K., Paraplegia, $1970,8,36$.

- Stone, N., and Meister, A., Nature, 1962, 194, 555.

5 Robertson, W. van B., in Connective Tissue: Intercellular Macromole-

cules, p. 93. Boston, Little Brown, 1964 .
Robertson, W. van B., and Hinds, H., fournal of Biological Chemistry, 1956, 221, 791 .

$1955,253,847$.

Hunter, T., and Rajan, K. T., Paraplegia, 1971, 8, 211.

\section{Chloroquine Myopathy}

Chloroquine phosphate and subsequently chloroquine sulphate were introduced for the treatment of malaria. They are relatively nontoxic and effective therapeutically and prophylactically in small doses. The chloroquine compounds have since been used in the treatment of rheumatoid arthritis and lupus erythematosus. Much larger doses for periods of a year or more have been followed by reports of toxic symptoms.

In a recent report ${ }^{1}$ of two cases of myopathy after administration of chloroquine the authors describe the clinical course and investigations of one patient with rheumatoid arthritis and another with sarcoidosis. The first patient received $400 \mathrm{mg}$ of chloroquine sulphate daily for two and a quarter years and the second $500 \mathrm{mg}$ daily for one and a half years. Both patients were also receiving steroids. The patient with rheumatoid arthritis developed progressive weakness of all limbs and some difficulty in swallowing. Her hair also went white three months after starting chloroquine. Wasting and weakness of all muscle groups, but worse in the region of the right shoulder, were accompanied by diminished tendon reflexes but no other signs. The wasting progressed after the steroids were stopped. She died of bronchopneumonia one month after the chloroquine was stopped. The second patient already had neurological lesions from sarcoid, con- firmed by biopsy of an indurated lesion on her left arm, with bilateral anosmia, optic atrophy, and spastic paraparesis, before starting chloroquine therapy. A year later weakness of her legs had increased, with distinct wasting and weakness of both quadriceps muscles.

Biopsy of an affected muscle confirmed the diagnosis in both cases. Conspicuous vacuolation throughout the whole of the muscle fibres, without any inflammatory change, was accompanied by histochemical changes in degenerating muscle fibres, with alteration in the adenosine triphosphatase and phosphorylase reactions. Instead of the normal positive reactions an alternation between negative and positive reactions was found along the fibres. The process was considered to be preferentially involving granular or type 1 muscle fibres. Experimental chloroquine myopathy shows a similar histochemical selectivity. ${ }^{2}$ Electron microscopy indicated that chloroquine attacks mitochondria. Moreover it is suggested that heart muscle, which is rich in mitochondria, as are the granular fibres of skeletal muscle, is always affected, and to a greater extent. ${ }^{3}$

As both patients were receiving steroids as well as chloroquine it is important to distinguish between steroid myopathy and chloroquine myopathy. The evidence of muscle biopsy with the typical histological and histochemical changes described above helps to distinguish chloroquine myopathy, and to this can be added the fact that chloroquine myopathy may be a severe toxic phenomenon in those receiving large doses over long periods.

\footnotetext{
${ }^{1}$ Hughes, J. T., Esiri, M., Oxbury, J. M., and Whitty, C. W. M., Quarterly Fournal of Medicine, 1971, 40, 85.

- Macdonald, R. D., and Engel, A. G., Fournal of Neuropathology and Experimental Neurology, 1970, 29, 479.

Smith, B., and O'Grady, F., Journal of Neurology, Neurosurgery and Psychiatry, 1966, 29, 255.
}

\section{No General Danger from Pets with Cancer}

There is a natural fear in the hearts of men that cancer may be contagious-from man to man or from pet animal to man. Increasing knowledge of the association between viruses and the development of cancers in various animal species has served to reinforce this fear during recent years. A particular cause for concern has been the discovery of C-type RNA viruses as initiating causes of lymphoma and sarcoma in cats. ${ }^{1-5}$ Anxiety was increased by the observation that feline RNA tumour viruses can infect and multiply in human cells growing in tissue culture ${ }^{6-8}$ and by the fact that C-type viruses have been seen in the electron microscope in the salivary gland of domestic cats with lymphoma-and indeed in the tissues of apparently healthy cats. ${ }^{9} 10$

A recent report of negative findings is therefore a source of some comfort. B. Hanes and his colleagues ${ }^{10}$ assumed that, if exposure to cats causes cancer in man, then a group of persons with cancers of types known to be associated with C-type viruses in cats would have a history of more exposure to cats than would a group of controls. Their conclusion, based on the results of two surveys involving altogether 530 households containing a person with cancer and 1,042 matched control households, was that there was no evidence of greater exposure to cats, dogs, or parakeets in the cancer households. They found 